\title{
The Meaning of Learning
}

\author{
Aisha Al-Hamiz Al-Suwaidi \\ Health Promotion student at Zayed University
}

I begin with the name of God, Allah, the Most Compassionate, the Most Merciful. This has been a great opportunity to reflect on my University courses, especially the one in which I really learnt a lot. The truth is, to learn a lot from a course means absolutely nothing, if we don't apply what we have learnt. As a second year student majoring in Health Promotion at Zayed University, I feel that I learnt a lot from the Arabic Lab (SBS 212) because it helped me apply my Arabic skills to real life issues.

The Lab aims to enable students to practice Modern Standard Arabic writing, reading and conversation skills. Coming from a private, American based high school in Abu Dhabi where English is the main language used, Arabic courses in $\mathrm{ZU}$ were a challenge. Improving the Arabic skills of students is one of ZU's aims because it is needed for their future career in the Emirates. Comparing myself to students at $\mathrm{ZU}$ with a high standard in Arabic language, (since many students come from public schools where Arabic is the main language used) I felt that this course would be very difficult; I felt scared. However, my dream and intention of being able to speak and write formal Arabic fluently has had an impact on my view, performance, and accomplishments in this course. One of the major assignments was producing a research paper accompanied by a 15-minute PowerPoint presentation. As a topic I chose "Improving Public Health for Children in the Emirates". In this assignment I have given recommendations on education, nutrition, and exercise to guardians, parents, schools, businesses, and organizations.

One of the greatest things I learnt throughout the course was in writing an effective paper the major aim is to show the truth; the aim is not to support my personal opinions, for there is a great distinction between the two: truth is more convincing and the strongest thing in knowledge is the truth. I also learnt that the greatest power I own is choice. For example, I choose to live and enjoy life's great colors and wonders. I believe that I am a good person simply because I exist. If I have a desire to live life to the fullest, I can choose to do so. And if I have a desire to be a good writer and speaker, I can also choose to be so.

When it came to presenting my research I felt fearful and nervous because it was my first time to speak in fluent Arabic for 15 minutes. I have never done that before. But at the same time, I felt that if everyone could to do it then I could do it also. To conquered my fears for sure, I sincerely supplicated to God before presenting with a feeling of trust; that only He has the power to help me because He is AlMujib, the Responder to Prayer, and He is Al-Raqib, the Watchful One. So I became confident and did not feel afraid like the first time I entered this course. I began my presentation just like I began this article, in the name of the Truth, Allah, the Most Compassionate, the Most Merciful. Then, I continued speaking fluently in formal Arabic. My presentation was successful and my messages were clear. I was very glad to receive an $A+$ on my assignment.

For the future I have plans to edit and publish my writings. This is because I spend a lot of time and effort on my work. I would love to see community action on children's nutrition. One thing I would emphasize is the importance of getting feedback from your professor or others: remember that in all courses, unfortunately, once the semester (before the summer holiday) ends, assignments and exams only get marked. In life when we don't receive (and accept) feedback, we don't realize, notice and change our mistakes. It is possible to repeat our mistakes over and over again if we don't stop, and think 
about the choices we make, think of possible solutions, take the opinions of others... and ultimately, moving forward is but a choice! 